\title{
The Use of Gadolinium-Carbon Nanostructures to Magnetically Enhance Stem Cell Retention for Cellular Cardiomyoplasty
}

\author{
Lesa A. Tran ${ }^{1}$, Mayra Hernández-Rivera ${ }^{1}$, Ari N. Berlin1, Yi Zheng², Luiz Sampaio², \\ Christina Bové ${ }^{2}$, Maria da Graça Cabreira-Hansen ${ }^{2}$, James T. Willerson ${ }^{2}$, Emerson C. \\ Perin ${ }^{2}$, and Lon J. Wilson ${ }^{1,}{ }^{*}$ \\ ${ }^{1}$ Department of Chemistry and the Smalley Institute for Nanoscale Science and Technology, \\ MS-60, P.O. Box 1892, Rice University, Houston, Texas 77251-1892, USA \\ ${ }^{2}$ Stem Cell Center, Texas Heart Institute at St. Luke's Episcopal Hospital, MC 2-255, P.O. Box \\ 20345, Houston, Texas 77225-0345, USA
}

\begin{abstract}
In this work, the effectiveness of using Gadonanotubes (GNTs) with an external magnetic field to improve retention of transplanted adult mesenchymal stem cells (MSCs) during cellular cardiomyoplasty was evaluated. As a high-performance $T_{1}$-weighted magnetic resonance imaging (MRI) cell tracking label, the GNTs are gadolinium-loaded carbon nanotube capsules that render MSCs magnetic when internalized. MSCs were internally labeled with either superparamagnetic GNTs or colloidal diamagnetic lutetium (Lu). In vitro cell rolling assays and ex vivo cardiac perfusion experiments qualitatively demonstrated increased magnetic-assisted retention of GNTlabeled MSCs. Subsequent in vivo epicardial cell injections were performed around a $1.3 \mathrm{~T} \mathrm{NdFeB}$ ring magnet sutured onto the left ventricle of female juvenile pigs $(n=21)$. Cell dosage, magnet exposure time, and endpoints were varied to evaluate the safety and efficacy of the proposed therapy. Quantification of retained cells in collected tissues by elemental analysis ( $\mathrm{Gd}$ or $\mathrm{Lu}$ ) showed that the external magnet helped retain nearly three times more GNT-labeled MSCs than Lu-labeled cells. The sutured magnet was tolerated for up to 168 hours; however, an inflammatory response to the magnet was noted after 48 hours. These proof-of-concept studies support the feasibility and value of using GNTs as a magnetic nanoparticle facilitator to improve cell retention during cellular cardiomyoplasty.
\end{abstract}

\section{Keywords}

Single-walled carbon nanotube; cellular cardiomyoplasty; Gadonanotube; mesenchymal stem cell; nanotechnology

\footnotetext{
(C) 2013 Elsevier Ltd. All rights reserved.

*Address for Correspondence: Lon J. Wilson, MS-60, P.O. Box 1892, Rice University, Houston, Texas, 77251-1892, USA; Tel: +1 713348 3476; Fax: +1 713348 5155; durango@ rice.edu.

Appendix

An additional figure documenting the ex vivo bovine heart study (Figure S1), the histographical distribution of each pig sample in the in vivo retention study (Figure S2), and a table detailing the parameters of the in vivo retention study (Table S1) can be found in the Supplementary Data section.

Publisher's Disclaimer: This is a PDF file of an unedited manuscript that has been accepted for publication. As a service to our customers we are providing this early version of the manuscript. The manuscript will undergo copyediting, typesetting, and review of the resulting proof before it is published in its final citable form. Please note that during the production process errors may be discovered which could affect the content, and all legal disclaimers that apply to the journal pertain.
} 


\section{Introduction}

Over the past decade, interest in cellular cardiomyoplasty for treating injured cardiac tissue has grown exponentially. Of the various cell types used for cellular cardiomyoplasty, adult bone marrow-derived mesenchymal stem cells (MSCs) are particularly attractive because of their allogeneic use, therapeutic potential, and ease of isolation and expansion [1].

Numerous preclinical and clinical studies have shown the benefits of transplanted adult bone marrow cells such as MSCs in cardiac repair [2,3]. However, the retention and survival of transplanted cells in the heart are severely limited by muscle contraction and blood flow at the injection site, which may reduce the benefits achieved with current cell transplantation approaches. In preclinical and clinical studies, immunohistochemical and radiolabeling techniques have shown that only 5-15\% of transplanted MSCs remain in the heart, regardless of the model, delivery method, and dosage level used [4-6].

In order to address these challenges in cellular cardiomyoplasty, several biochemical approaches have been studied to improve the retention and survival of transplanted cells in the myocardium. These include transgenically enhancing protein secretion, conditioning cells in vitro to improve survival, exploiting endogenous mechanisms to increase homing, and targeting tissues with antibodies and proteins to increase cell adhesion and engraftment $[7,8]$. However, the clinical translation of such methods may be difficult.

To help cells withstand the mechanical challenges in the heart, physical methods have been developed such as transplanting cells embedded in hydrogels, delivering cell sheet fragments, or using 3D constructs [9-11]. One physical approach that has been clinically translatable and effective in improving cell homing and retention is the magnetic targeting of superparamagnetic iron oxide-labeled cells to grafts, stents, and cardiac tissue under an external magnetic field [12-14]. An additional benefit of using iron-oxide particles is their performance as a $\mathrm{T}_{2}$-weighted cellular label for magnetic resonance imaging (MRI), which enables noninvasive, real-time visualization of the transplanted cells. However, internally labeling cells with iron-oxide particles usually requires the use of polycationic transfection agents, many of which have been shown to affect MSC differentiation and are considered cytotoxic when used in high concentrations $[15,16]$. Furthermore, the darkening effects of $\mathrm{T}_{2}$-weighted agents may not be ideal for enhancing visual details, as compared to $\mathrm{T}_{1^{-}}$ weighted MRI agents, which brighten images.

The Gadonanotubes (GNTs) are a high-performance $\mathrm{T}_{1}$-weighted MRI contrast agent and an effective cellular magnetic probe that may have the potential to address the limitations of cell therapy. These gadolinium $\left(\mathrm{Gd}^{3+}\right)$ ion-containing carbon nanocapsules possess the highest recorded $\mathrm{T}_{1}$-weighted relaxivity to date at a clinically relevant field, with a value of $170 \mathrm{mM}^{-1} \mathrm{~s}^{-1}$ per $\mathrm{Gd}^{3+}$ ion $\left(37^{\circ} \mathrm{C}, 1.5 \mathrm{~T}\right)[17,18]$. It was also recently established that the empty carbon nanocapsule component of the GNTs can serve as a $\mathrm{T}_{2}$-weighted contrast agent, due to residual metal oxide catalyst found within the carbon nanotube capsule sidewall [19]. Previous studies demonstrated that the $\mathrm{Gd}^{3+}$ ion clusters within the GNTs remained stable and intact after exposure to physiological challenges, which alleviates concerns of heavy metal ion loss that other $\mathrm{Gd}^{3+}$-based contrast agents may exhibit [18]. Moreover, the nanoscale length and unusually high aspect ratio of GNTs allow them to be rapidly internalized by mammalian cells, such as breast cancer cells, MSCs, and macrophages, without the need of a transfection agent [20-22]. Recent studies have shown that GNTs do not affect the viability, differentiation potential, or phenotype of MSCs when used as an intracellular MRI label [21]. In addition to being a biocompatible and effective MRI cell-labeling agent, the inherently magnetic GNTs, when internalized by MSCs, can render the cells magnetically attracted to external magnetic fields. This characteristic 
enables the magnetic retention of the GNT-labeled MSCs in cardiac tissue for cellular cardiomyoplasty.

Although over 2,000 stem cell-based clinical trials are currently underway [23], the retention and survival of transplanted cells at target sites remain major challenges. As such, innovative and translatable strategies to improve cell retention and survival within the heart, which should lead to better therapeutic outcomes, are highly desirable for cellular cardiomyoplasty. In the present proof-of-concept study, in vitro, ex vivo, and in vivo experiments were conducted to examine the magnetically driven, therapeutic potential of GNTs as a $\mathrm{T}_{1}$-weighted magnetic nanoparticle facilitator for improving transplanted cell retention during cellular cardiomyoplasty. Cell dosage, magnetic exposure time, and endpoints were varied to determine the safety and efficacy of the proposed therapy in porcine models.

\section{Materials and Methods}

\section{Cell culture and labeling}

MSCs were isolated from the bone marrow of male pigs as described elsewhere [24] and were grown in alpha-modified minimum essential medium (aMEM) containing 10\% FBS and $1 \%$ antibiotic supplement $(200 \mathrm{mM}$ L-glutamine, 10,000 units/mL penicillin, and 10 $\mathrm{mg} / \mathrm{mL}$ streptomycin) at $37{ }^{\circ} \mathrm{C}\left(95 \%\right.$ relative humidity in $\left.5 \% \mathrm{CO}_{2}\right)$. MSCs were expanded by two successive passages $(\mathrm{P})$ at $2 \times 10^{3}$ cells $/ \mathrm{cm}^{2}$ and then frozen at $\mathrm{P}_{2}$ in cryovials in $10 \%$ DMSO/90\% FBS. At appropriate times, cells were thawed and expanded once $\left(\mathrm{P}_{3}\right)$ before labeling. All labeling studies were performed with $\mathrm{P}_{3}$ MSCs grown to $70 \%$ confluence in tissue culture flasks $\left(175 \mathrm{~cm}^{2}\right)$. Three MSC cultures were separately labeled as described below; unlabeled cells were used as control cells for the in vitro studies. Cell concentrations were verified by a Beckman Coulter MultiSizer 3.

\section{GNT-labeled MSCs}

GNTs were produced and suspended in an aqueous solution of Pluronic F108 $(0.17 \%$, BASF) as previously reported [21]. MSCs were then incubated in the GNT-labeling solution $\left(27 \mu \mathrm{M} \mathrm{Gd}^{3+}\right)$ for 24 hours. Cells were isolated from excess GNTs in solution by density gradient centrifugation. Briefly, Histopaque 1077 (25 ${ }^{\circ} \mathrm{C}$, Sigma-Aldrich) was slowly added to the bottom of the tube at a 1:2 ratio (Histopaque:cell suspension). The sample was centrifuged at $400 \times \mathrm{g}$ for 20 minutes. GNT-labeled MSCs located at the interface of the aMEM and Histopaque phases were isolated, washed with PBS, and centrifuged at $285 \times \mathrm{g}$ for 10 minutes.

\section{USPIO-labeled MSCs}

USPIO nanoparticles (125 $\mu \mathrm{L})$ (Molday ION(-); 10 mg Fe/mL; Biophysics Assay

Laboratory, Inc., Worcester, MA) were diluted with $400 \mu \mathrm{L}$ cell culture grade water. To this solution, $12.5 \mu \mathrm{L}$ poly-L-lysine $(10 \mathrm{mg} / \mathrm{mL}$; Biophysics Assay Laboratory, Inc.) was added. The USPIO-poly-L-lysine conjugate solution was gently mixed by using a vortex, incubated at $25^{\circ} \mathrm{C}$ for 20 minutes, and stored at $4{ }^{\circ} \mathrm{C}$. Before cell labeling, the solution was mixed again, incubated at $25^{\circ} \mathrm{C}$ for 20 minutes, diluted in $12 \mathrm{~mL}$ aMEM, and thoroughly mixed. The SPIO-poly-L-lysine solution was added to $12.5 \mathrm{~mL}$ aMEM into each cell culture flask to yield a final concentration of $50 \mu \mathrm{g} \mathrm{Fe} / \mathrm{mL}$ and $5 \mu \mathrm{g} / \mathrm{mL}$ poly-L-lysine. After incubation for 24 hours, cells were washed thoroughly with PBS and were lifted by using trypsinEDTA for 5 minutes. The cell suspension was then passed through a $70 \mu \mathrm{m}$ nylon filter to remove large cell aggregates. 


\section{Lu-labeled MSCs}

MSCs were incubated in $2 \mathrm{v} / \mathrm{v} \%$ colloidal $\mathrm{Lu}(20 \mathrm{~nm}$; BioPAL CellTrackTM; Biophysics Assay Laboratory, Inc.) for 24 hours in aMEM. Cells were washed thoroughly with PBS and were lifted by using trypsin-EDTA for $5 \mathrm{~min}$. The cell suspension was then passed through a $70 \mu \mathrm{m}$ nylon filter to remove large cell aggregates.

\section{In vitro magnetic cell retention assay}

GNT-labeled MSCs, USPIO-labeled MSCs, and unlabeled MSCs were separately prepared at $5 \times 10^{5}$ cells $/ \mathrm{mL}$ in running buffer $\left(10 \mathrm{mM}\right.$ Tris, $103 \mathrm{mM} \mathrm{NaCl}, 24 \mathrm{mM} \mathrm{NaHCO}_{3}, 5.5 \mathrm{mM}$ glucose, $5.4 \mathrm{mM} \mathrm{KCl}$ and $2 \mathrm{mg} / \mathrm{mL}$ bovine serum albumin [BSA], $\mathrm{pH}$ 7.4). Cells were examined in a modified parallel-plate flow-fluid shear stress rolling assay [25]. Briefly, $24 \times 50 \mathrm{~mm}$ slides were cut from $15 \times 100 \mathrm{~mm}$ polystyrene Petri dishes. The slides were washed with PBS, blocked with $2 \%$ BSA for 2 hours at $25^{\circ} \mathrm{C}$ and assembled in a parallelplate flow chamber. To assess the magnetic retention of MSCs, a $1.3 \mathrm{~T}$ ring $\mathrm{NdFeB}$ magnet (RX4C2, K\&J Magnetics) was affixed to the slide. Cells were injected into the flow chamber, and running buffer was drawn through the chamber at a constant force of 1 dyne/ $\mathrm{cm}^{2}$ for 5 minutes by using a computer-controlled syringe pump (Harvard Apparatus). The number of adherent cells remaining was recorded by digital microscopy (VI-470 chargecoupled device video camera; Optronics Engineering) at 20× on an inverted Nikon DIAPHOT-TMD microscope. The buffer solution that was passed through the chamber was collected and centrifuged to recover cells that were not magnetically retained in the chamber. The recovered cells were fixed with 2\% paraformaldehyde in PBS and analyzed by flow cytometry (FACS Calibur BD) with the use of a forward and side scatter gate to distinguish live cells. The number of gated events was used to quantify recovered cells (\% of cells not retained in the chamber by the magnet), which was used to determine the amount of magnetically adherent cells (\% of cells magnetically retained in the chamber).

\section{Ex vivo perfusion study}

Separate $0.2 \mathrm{~mL}$ transepicardial bolus cell injections $\left(100 \times 10^{6}\right.$ cells $/ \mathrm{mL}$ in $2 \%$ FBS $)$ of the following cell populations were administered approximately $5 \mathrm{~mm}$ into the left ventricle of an excised bovine heart: (1) GNT-labeled MSCs with a 1.3 T cylindrical NdFeB magnet (D66SH; K\&J Magnetics) held in place over the injection site, (2) GNT-labeled MSCs without a magnet, and (3) unlabeled MSCs. (Refer to Figure S1 in the Supplementary Data.) The heart was perfused with cold saline solution for 72 hours, maintained in $10 \%$ formalin for 24 hours, and prepared for histopathologic analysis. A $1.7 \mathrm{~cm}$ slice perpendicular to the long axis of the heart was obtained approximately $6 \mathrm{~mm}$ above and $6 \mathrm{~mm}$ below the suture marks. The portion of wall containing each injection site was removed from the slice and sectioned into 5 levels. Adjacent tissue sections were stained with hematoxylin and eosin.

\section{In vivo retention study}

For in vivo studies, animals were cared for in accordance with the Institutional Animal Care and Use Committee (IACUC) guidelines of the Texas Heart Institute. GNT-labeled MSCs and Lu-labeled MSCs were separately suspended in $2 \%$ FBS and maintained on ice in sterile polystyrene tubes until injection. Three aliquots $\left(0.2-2 \times 10^{6}\right)$ of each cell population were also collected in glass scintillation vials for elemental analysis. A left thoracotomy was performed on female juvenile domestic pigs $(n=21)$ under general anesthesia. A sterilized $1.3 \mathrm{~T} \mathrm{NdFeB}$ ring magnet (RX4C2; K\&J Magnetics) was sutured with prolene stitches onto the anterior wall of the left ventricle. Cells were gently pipetted before transepicardial injections, which were completed with a 21 -gauge butterfly needle around the inner and outer perimeters of the ring magnet approximately $5 \mathrm{~mm}$ into the tissue. The pigs were divided into 7 groups (Groups A-G; $\mathrm{n}=3$ per group) in which the cell doses, magnetic 
exposure times, and study endpoint times varied (see Table S1 in the Supplementary Data for details). After cell injections, the implanted magnet remained in the animals for the entire duration of the study in Groups A-C: pigs in Group A were maintained on the operating table for 1 hour, but pigs in Groups B and C were allowed to recover following cell transplantation until they were euthanized at 48 and 168 hours, respectively. These time points were assessed to evaluate whether exceptionally long magnetic exposure times had any retention advantage compared to shorter times. (i.e. $<24$ hours). In Groups D-G, the pigs were maintained in the operating room with the sutured magnet for varying times (0.5-4 hours) following cell injections and were allowed to recover until being euthanized 24 hours after cell transplantation. Euthanasia was performed in a manner consistent with the Report of the American Veterinary Medical Association Panel on Euthanasia. The injection sites at the left ventricle, a corresponding portion of the right ventricle, and the paratracheal/ periaortic lymph nodes were collected for analysis from all pigs.

\section{Sample digestion and elemental analysis}

All tissue samples were frozen for 24 hours and lyophilized for 48 hours to remove all water content. Diced tissue samples were slowly added to $70 \%$ trace-metal grade $\mathrm{HNO}_{3}$ in Erlenmeyer flasks with borosilicate beads at $110^{\circ} \mathrm{C}$ until all tissues were completely dissolved. Tissue samples were dried for 12 hours at $220^{\circ} \mathrm{C}$ and then treated twice with alternating additions of $70 \%$ trace-metal grade $\mathrm{HNO}_{3}$ and $25 \% \mathrm{HClO}_{3}$ at $110{ }^{\circ} \mathrm{C}$, allowing for samples to dry in between each acid addition. Samples were cooled, diluted to $30 \mathrm{~mL}$ with $2 \%$ trace-metal grade $\mathrm{HNO}_{3}$, and filtered through a $0.22 \mu \mathrm{m}$ syringe filter. Cell samples were heated with two alternating additions of $500 \mu \mathrm{L} 70 \%$ trace-metal grade $\mathrm{HNO}_{3}$ and $25 \%$ $\mathrm{HClO}_{3}$ until boiling, allowing samples to dry between each addition. The digested samples were then diluted to $10 \mathrm{~mL}$ with $2 \%$ trace-metal grade $\mathrm{HNO}_{3}$ and filtered through a $0.22 \mu \mathrm{m}$ syringe filter.

Inductively-coupled plasma mass spectrometry analyses were performed by using a PerkinElmer Elan 9000 Inductively-Coupled Plasma Mass Spectrometer (Waltham, MA). The average metal ion uptake by each cell was calculated by using the concentration of $\mathrm{Gd}^{3+}$ or $\mathrm{Lu}^{3+}$ ions and the total cell number in each sample, and this was used to calculate the amount of cells retained in tissue samples.

\section{Statistical analysis}

Unless otherwise noted, all experiments were conducted in triplicate and all results are presented as mean \pm standard deviation. Any two populations $(\mathrm{n}=3)$ in the in vitro studies were compared using the two-tailed Mann-Whitney $\mathrm{U}$ test, while any two populations ( $\mathrm{n}=$ 3 ) in the in vivo studies were compared using the one-tailed Mann-Whitney U test. To normalize differences in cell dose between sample groups, results are reported in cell population percentages. While the calculation of a meaningful $p$ value for only $n=3$ may not be deemed appropriate, $\mathrm{p}$ values were, however, calculated for the reader's interest.

\section{Results}

\section{In vitro magnetic cell retention assay}

To assess whether cellular magnetic labels, such as GNTs or alternatively ultrasmall paramagnetic iron oxide particles (USPIOs), render MSCs magnetically active, a modified parallel-plate fluid flow chamber rolling assay was performed. This assay is conventionally used to evaluate cell adhesion movement over various proteins and other small molecules that have been immobilized on a glass slide over which a fluid sheer stress is applied to mimic the dynamic fluid flow in a physiological environment [25]. In the present study, rather than studying chemical adhesion, we examined the magnetic retention of GNT- 
labeled MSCs, USPIO-labeled MSCs, and unlabeled MSCs by a $1.3 \mathrm{~T} \mathrm{NdFeB} \mathrm{ring} \mathrm{magnet}$ attached to the underside of the glass slide. Because a similar study concluded that both unlabeled MSCs and Lu-labeled MSCs showed negligible attraction to the external magnet (results not reported), both populations were considered as negative controls for future experiments. Under a constant fluid shear force of 1 dyne $/ \mathrm{cm}^{2}$ for $5 \mathrm{~min}$, significantly more GNT-labeled MSCs and USPIO-labeled MSCs were magnetically retained on the slide compared with unlabeled cells (Figure 1). Although significantly more USPIO-labeled cells than GNT-labeled MSCs were magnetically adherent (91\% vs. 57\%; $<<0.05)$, the GNTlabeled MSCs demonstrated a significant attraction to an external magnetic field when compared to unlabeled cells ( $57 \%$ vs. $4 \%$; $p<0.05$ ), even when challenged under similar conditions of mechanical stress as normally experienced by vascular smooth muscle cells [26]. For this reason and because of the $\mathrm{T}_{1}$-weighted MRI advantage that the GNTs will offer over USPIOs for planned future studies, we chose to use GNT-labeled MSCs for our initial ex vivo and in vivo studies.

\section{Ex vivo perfusion study}

Ex vivo perfusion studies were performed on bovine hearts, which were conveniently available at the time of the experiment, to demonstrate that the proximity of an external magnet improves the retention of GNT-labeled MSCs injected into cardiac muscle. After 72 hours of saline perfusion, we observed drainage of the dark GNT-labeled MSCs in the epicardial vein above Injection Site 2 (Figure 2a). Histopathologic analysis of the bovine heart indicated that the external magnet assisted in concentrating the injected GNT-labeled MSCs at the target site because both unlabeled MSCs and GNT-labeled MSCs without a magnet disseminated throughout the tissue and vasculature (Figures $3 \mathrm{~b}$ and c). In addition, the tissue containing Injection Site 1 showed an area of GNT-labeled MSCs about 4-5 mm in diameter located approximately $5 \mathrm{~mm}$ from the epicardial surface. Microscopic analysis showed concentrated clusters of GNT-labeled MSCs at interstitial spaces, with few signs of additional dissemination. In contrast, at Injection Site 2, a smaller area of GNT-labeled MSCs of approximately $3 \mathrm{~mm}$ in diameter consisting of several small black clusters was located less than $2 \mathrm{~mm}$ from the epicardial surface. The subendocardial region showed areas of grayish discoloration, suggesting the presence of disseminated GNT-labeled MSCs (Figure 2c). GNT-labeled MSCs were found in interstitial spaces in smaller clusters than those at Injection Site 1, as well as in the lumen of various epicardial capillaries and veins. Similarly, Injection Site 3 showed small clusters of unlabeled MSCs approximately $2 \mathrm{~mm}$ from the epicardial surface. Dissemination of the MSCs was also apparent throughout various nearby venous cavities.

\section{In vivo retention study}

To simultaneously assess the retention efficiency of magnetically facilitated cell injections and the biocompatibility of a strong magnet sutured onto the left ventricular epicardium, we studied the effects of cell dosage and time of magnetic exposure in seven groups of pigs (Figure 3 and Table S1 in the Supplementary Data). In addition to being a well-established safety and efficacy model for cardiovascular studies, swine are preferred over smaller animal models (such as mice and rates) for their similarities to human cardiovascular anatomy, physiology, and remodeling kinetics [27-29]. Short- and long-term (1-168 hours) tolerance of the magnet were examined in Groups A-C, whereas Groups D-G were used to assess the optimal amount of time needed (0.5-4 hours) for the magnet to be applied to the heart before the pigs were euthanized 24 hours after cell injection. MSCs labeled with diamagnetic colloidal lutetium ( $\mathrm{Lu}$ ), which can be quantifiable upon elemental analysis, were used as controls. 
The in vivo experiments indicated that the suturing of a strong magnet to the epicardium was safe and feasible. No pig in any group died prematurely or showed signs of physiologic or behavioral distress during the study. However, an inflammatory response was observed around the magnet in Groups B and C (the longest magnet exposure times; 48 and 168 hours, respectively) (Figure 3c).

Furthermore, the in vivo injection studies indicated that magnetic facilitation improves transplanted MSC retention at target injection sites in the heart, supporting the ex vivo perfusion analysis. The retention efficiency of GNT-labeled MSCs was nearly three times higher than that of Lu-labeled MSCs (Figure 4). Although one of every three pigs in each group retained equivalent amounts of GNT-labeled MSCs and Lu-labeled MSCs at the injection site (Figure S2 in the Supplementary Data), most pigs retained between 1.7 to 3.6 times more GNT-labeled MSCs than Lu-labeled MSC controls, regardless of magnet exposure or study endpoint. This is similar to the retention rates exhibited by magnetically targeted iron-labeled cardiosphere-derived cells injected into mouse hearts after 24 hours [13]. Interestingly, a significant amount of GNT-labeled MSCs was detected in the right ventricle and the paratracheal/periaortic lymph nodes; however, negligible amounts of Lulabeled MSCs were detected in the control tissue samples, suggesting that most of these cells are lost by vasculature flow. There was no clear retention advantage to longer magnet application times (> 24 hours), but cell retention doubled when the magnetic exposure time was increased from $0.5-4$ hours.

\section{Discussion}

Along with being developed as an intracellular MRI agent, GNTs can be used as a magnetic facilitator to improve transplanted cell retention during cellular cardiomyoplasty. In the present study, the results from the in vitro and ex vivo experiments support the hypothesis that an applied external magnetic field can assist in concentrating GNT-labeled MSCs at targeted sites of injection. The completed in vivo porcine injection studies further corroborated these findings, demonstrating that GNTs improve the retention of transplanted cells by approximately three times more than Lu-labeled MSCs in cardiac tissue. While the epicardial implantation of a strong magnet onto the heart was tolerated for up to 168 hours, there was no significant retention advantage to extending the magnet exposure time beyond 4 hours after cell injection, which is a more practical timeframe for the clinical setting.

Nevertheless, more work is needed to improve the feasibility and translatability of the method described. Conventionally, transendocardial and intracoronary injections are preferred for cardiac stem cell therapy to keep procedures as minimally invasive as possible [30]. The transepicardial injections performed for this study are not a practical, efficient means of cell transplantation. During the experiments, we noted a dark gray residue, suggestive of GNT-labeled MSCs on the surface of the sutured magnet after tissue extraction. This observation implies that the magnet may be extracting GNT-labeled cells through the channels created by the syringe needle over time. Along with being a much less invasive approach, the endocardial delivery of cells may reduce cell loss, since performing transendocardial injections around an epicardially sutured magnet would allow for the cardiac muscle to physically separate the magnet from the injected cells. Additionally, our laboratories are currently working towards the goal of developing a less invasive method to introduce an external magnetic source to cell injection sites, as opposed to the currently proposed method of implanting a strong permanent magnet to the heart. When using GNTlabeled MSCs effectively for cellular cardiomyoplasty, the ideal therapeutic procedure must use a biocompatible and minimally invasive magnetic source that is clinically practical (i.e., does not interfere with surgical procedures or medical equipment) for as short of a time period as possible. 
Other experimental variables must also be optimized to determine the most effective method of cell transplantation and magnetic retention. The optimal cell type, cell dose, timing of delivery, location of delivery, and delivery technique have not been identified for cardiac cell therapy [31]. These factors must first be determined in order to better realize the benefit of magnetically facilitating cell retention with an external magnetic source. In addition to increasing the number of test samples in each experiment to provide more statistically relevant results, more studies in ischemic porcine models are needed to provide results that better approximate the physiological conditions seen in patients' hearts and to better assess the overall effectiveness of magnetic cell retention.

In the present study, elemental analyses of extracted tissues were used in the quantitative studies; however, MRI visualization would be preferred in the clinical setting as a noninvasive method to quantify the retention and survival of transplanted GNT-labeled MSCs in the heart. Although MRI analysis was not performed in this study because the presence of the sutured magnet would interfere with imaging, our laboratories are currently exploring the 'theranostic' potential of the GNTs by interfacing the in vivo retention studies with concurrent MRI tracking experiments of the engrafted cells in animal models. Both $\mathrm{T}_{1^{-}}$ and $\mathrm{T}_{2}$-weighted imaging studies of GNT-labeled MSCs may be necessary [17,19], and long-term studies should also assess MSC integration into cardiac tissue and functional improvement.

\section{Conclusions}

Although the present study requires further refinement to become more clinically relevant, we provide here the preclinical proof of concept that the GNTs are a viable magnetic nanoparticle facilitator for cellular cardiomyoplasty. In the presence of an external magnetic field, GNTs can help safely and effectively increase cell retention at target cardiac sites. As an effective $\mathrm{T}_{1}$-weighted MRI-active magnetic nanoparticle facilitator, the GNTs may greatly improve the efficacy of current cell therapies for the treatment of cardiovascular disease, while allowing for long-term in vivo tracking of labeled stem cells by MRI.

\section{Supplementary Material}

Refer to Web version on PubMed Central for supplementary material.

\section{Acknowledgments}

The authors thank Deborah Vela for histopathologic analyses, Bradley McIntyre and Wells Brown for assistance with the rolling assays, Rebecca Bartow for editorial assistance, and the Cardiovascular Research Laboratories at the Texas Heart Institute for assistance in the ex vivo and in vivo studies. This work was supported by an NIH Challenge Grant (1RC1EB010791-01), an NSF Graduate Research Fellowship (DGE-0940902, LAT), the Welch Foundation (C-0627), and the Nanoscale Science and Engineering Initiative of the NSF at Rice University (EEC-0647452).

\section{References}

1. Kassem M, Kristiansen M, Abdallah BM. Mesenchymal stem cells: cell biology and potential use in therapy. Basic Clin Pharmacol Toxicol. 2004; 95:209-14. [PubMed: 15546474]

2. Shake JG, Gruber PJ, Baumgartner WA, Senechal G, Meyers J, Redmond JM, et al. Mesenchymal stem cell implantation in a swine myocardial infarct model: engraftment and functional effects. Ann Thorac Surg. 2002; 73:1919-26. [PubMed: 12078791]

3. Abdel-Latif A, Bolli R, Tleyjeh IM, Montori VM, Perin EC, Hornung CA, et al. Adult bone marrow-derived cells for cardiac repair: a systematic review and meta-analysis. Arch Intern Med. 2007; 167:989-97. [PubMed: 17533201] 
4. Hou D, Youssef EA-S, Brinton TJ, Zhang P, Rogers P, Price ET, et al. Radiolabeled cell distribution after intramyocardial, intracoronary, and interstitial retrograde coronary venous delivery: implications for current clinical trials. Circulation. 2005; 112:I150-156. [PubMed: 16159808]

5. Freyman T, Polin G, Osman H, Crary J, Lu M, Cheng L, et al. A quantitative, randomized study evaluating three methods of mesenchymal stem cell delivery following myocardial infarction. Eur Heart J. 2006; 27:1114-22. [PubMed: 16510464]

6. Perin EC, Silva GV, Assad JAR, Vela D, Buja LM, Sousa ALS, et al. Comparison of intracoronary and transendocardial delivery of allogeneic mesenchymal cells in a canine model of acute myocardial infarction. J Mol Cell Cardiol. 2008; 44:486-95. [PubMed: 18061611]

7. Wagner J, Kean T, Young R, Dennis JE, Caplan AI. Optimizing mesenchymal stem cell-based therapeutics. Curr Opin Biotechnol. 2009; 20:531-6. [PubMed: 19783424]

8. Chavakis E, Koyanagi M, Dimmeler S. Enhancing the outcome of cell therapy for cardiac repair: progress from bench to bedside and back. Circulation. 2010; 121:325-35. [PubMed: 20083719]

9. Lee W-Y, Wei H-J, Lin W-W, Yeh Y-C, Hwang S-M, Wang J-J, et al. Enhancement of cell retention and functional benefits in myocardial infarction using human amniotic-fluid stem-cell bodies enriched with endogenous ECM. Biomaterials. 2011; 32:5558-67. [PubMed: 21555151]

10. Huang C-C, Tsai H-W, Lee W-Y, Lin W-W, Chen D-Y, Hung Y-W, et al. A translational approach in using cell sheet fragments of autologous bone marrow-derived mesenchymal stem cells for cellular cardiomyoplasty in a porcine model. Biomaterials. 2013; 34:4582-91. [PubMed: 23528228]

11. Li T-S, Cheng K, Lee S-T, Matsushita S, Davis D, Malliaras K, et al. Cardiospheres recapitulate a niche-like microenvironment rich in stemness and cell-matrix interactions, rationalizing their enhanced functional potency for myocardial repair. Stem Cells. 2010; 28:2088-98. [PubMed: 20882531]

12. Consigny PM, Silverberg DA, Vitali NJ. Use of endothelial cells containing superparamagnetic microspheres to improve endothelial cell delivery to arterial surfaces after angioplasty. J Vasc Interv Radiol. 1999; 10:155-63. [PubMed: 10082102]

13. Cheng K, Li T-S, Malliaras K, Davis DR, Zhang Y, Marbán E. Magnetic targeting enhances engraftment and functional benefit of iron-labeled cardiosphere-derived cells in myocardial infarction. Circulation Res. 2010; 106:1570-81. [PubMed: 20378859]

14. Cheng K, Malliaras K, Li T-S, Sun B, Houde C, Galang G, et al. Magnetic enhancement of cell retention, engraftment, and functional benefit after intracoronary delivery of cardiac-derived stem cells in a rat model of ischemia/reperfusion. Cell Transplant. 2012; 21:1121-35. [PubMed: 22405128]

15. Arbab AS, Yocum GT, Wilson LB, Parwana A, Jordan EK, Kalish H, et al. Comparison of transfection agents in forming complexes with ferumoxides, cell labeling efficiency, and cellular viability. Mol Imaging. 2004; 3:24-32. [PubMed: 15142409]

16. Bulte JWM, Kraitchman DL. Iron oxide MR contrast agents for molecular and cellular imaging. NMR Biomed. 2004; 17:484-99. [PubMed: 15526347]

17. Sitharaman B, Kissell KR, Hartman KB, Tran LA, Baikalov A, Rusakova I, et al. Superparamagnetic gadonanotubes are high-performance MRI contrast agents. Chem Commun. 2005:3915.

18. Hartman KB, Laus S, Bolskar RD, Muthupillai R, Helm L, Toth E, et al. Gadonanotubes as ultrasensitive pH-smart probes for magnetic resonance imaging. Nano Lett. 2008; 8:415-9. [PubMed: 18215084]

19. Ananta JS, Matson ML, Tang AM, Mandal T, Lin S, Wong K, et al. Single-walled carbon nanotube materials as $\mathrm{T}_{2}$-weighted MRI contrast agents. J Phys Chem C. 2009; 113:19369-72.

20. Hassan AA, Chan BT-Y, Tran LA, Hartman KB, Ananta JS, Mackeyev Y, et al. Serine-derivatized gadonanotubes as magnetic nanoprobes for intracellular labeling. Contrast Media Mol Imaging. 2010; 5:34-8. [PubMed: 20101755]

21. Tran LA, Krishnamurthy R, Muthupillai R, da Graça Cabreira-Hansen M, Willerson JT, Perin EC, et al. Gadonanotubes as magnetic nanolabels for stem cell detection. Biomaterials. 2010; 31:948291. [PubMed: 20965562] 
22. Tang AM, Ananta JS, Zhao H, Cisneros BT, Lam EY, Wong ST, et al. Cellular uptake and imaging studies of gadolinium-loaded single-walled carbon nanotubes as MRI contrast agents. Contrast Media Mol Imaging. 2011; 6:93-9. [PubMed: 21504063]

23. Ferreira L, Karp JM, Nobre L, Langer R. New opportunities: the use of nanotechnologies to manipulate and track stem cells. Cell Stem Cell. 2008; 3:136-46. [PubMed: 18682237]

24. Bosch P, Pratt SL, Stice SL. Isolation, characterization, gene modification, and nuclear reprogramming of porcine mesenchymal stem cells. Biol Reprod. 2006; 74:46-57. [PubMed: 16162872]

25. Woodside DG, Kram RM, Mitchell JS, Belsom T, Billard MJ, McIntyre BW, et al. Contrasting roles for domain 4 of VCAM-1 in the regulation of cell adhesion and soluble VCAM-1 binding to integrin a4ß1. J Immunol. 2006; 176:5041-9. [PubMed: 16585601]

26. Wang DM, Tarbell JM. Modeling interstitial flow in an artery wall allows estimation of wall shear stress on smooth muscle cells. J Biomech Eng. 1995; 117:358-63. [PubMed: 8618390]

27. Dixon JA, Spinale FG. Large animal models of heart failure: a critical link in the translation of basic science to clinical practice. Circ Heart Fail. 2009; 2:262-71. [PubMed: 19808348]

28. Suzuki Y, Yeung AC, Ikeno F. The representative porcine model for human cardiovascular disease. J Biomed Biotechnol. 2011; 2011:195483. [PubMed: 21253493]

29. Gandolfi F, Vanelli A, Pennarossa G, Rahaman M, Acocella F, Brevini TaL. Large animal models for cardiac stem cell therapies. Theriogenology. 2011; 75:1416-25. [PubMed: 21463721]

30. Perin EC, Dohmann HFR, Borojevic R, Silva SA, Sousa ALS, Mesquita CT, et al.

Transendocardial, autologous bone marrow cell transplantation for severe, chronic ischemic heart failure. Circulation. 2003; 107:2294-302. [PubMed: 12707230]

31. Hamamoto H, Gorman JH 3rd, Ryan LP, Hinmon R, Martens TP, Schuster MD, et al. Allogeneic mesenchymal precursor cell therapy to limit remodeling after myocardial infarction: the effect of cell dosage. Ann Thorac Surg. 2009; 87:794-801. [PubMed: 19231391] 


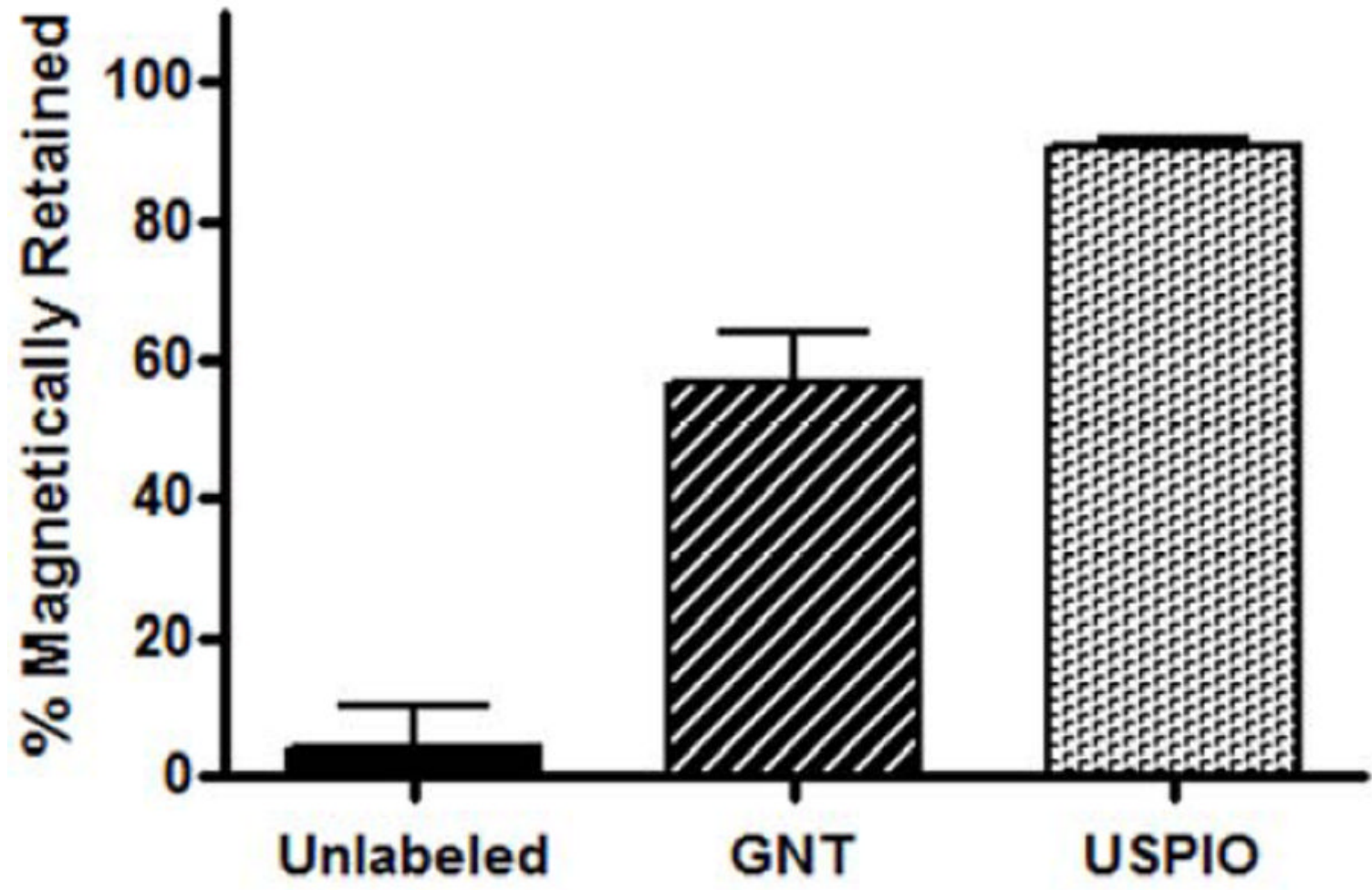

Figure 1.

The In Vitro Cell Rolling Assay Results. Magnetic retention of unlabeled MSC, GNTlabeled MSCs, and USPIO-labeled MSCs in a modified parallel-plate fluid flow chamber rolling assay. All populations were statistically significant $(\mathrm{p}<0.05)$ from each other. 
a.

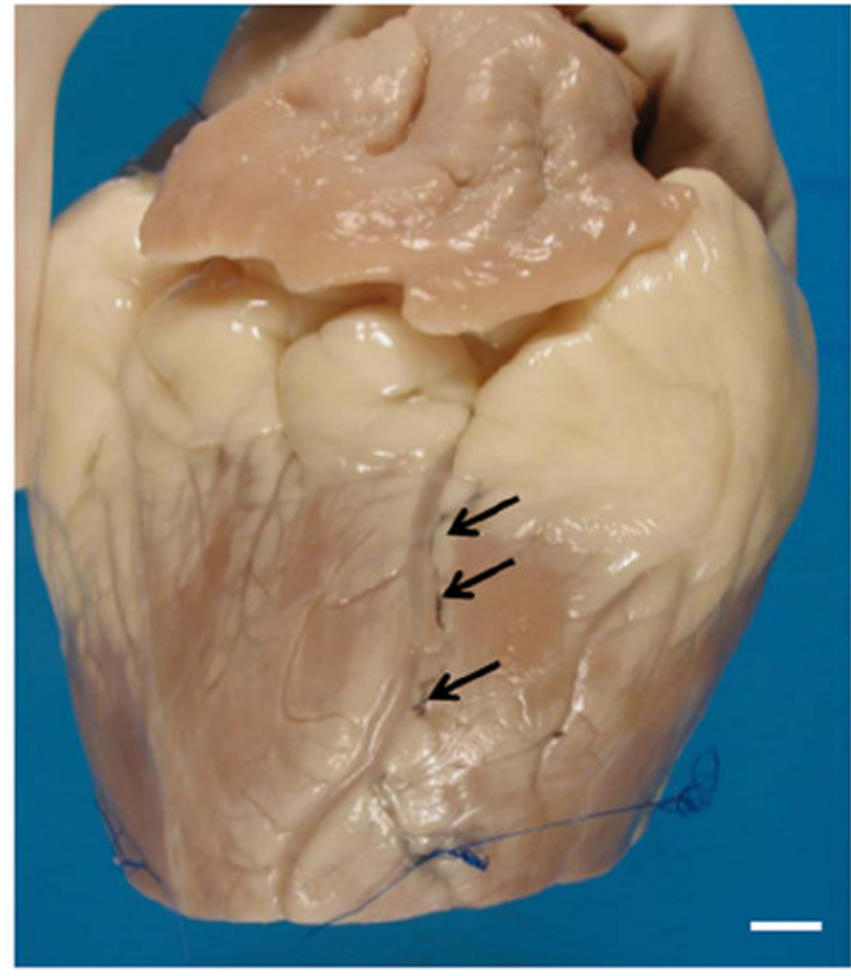

b.
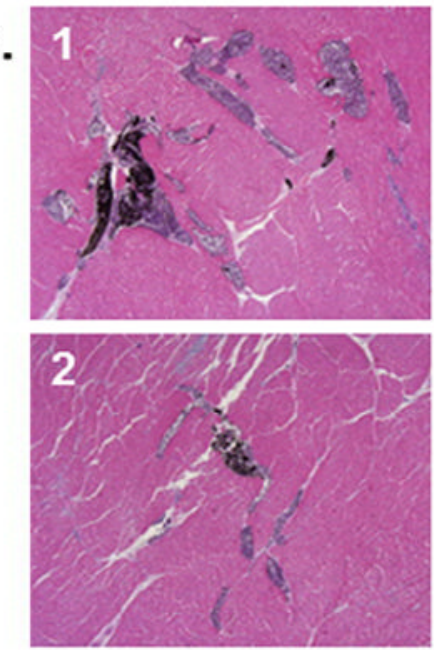

3

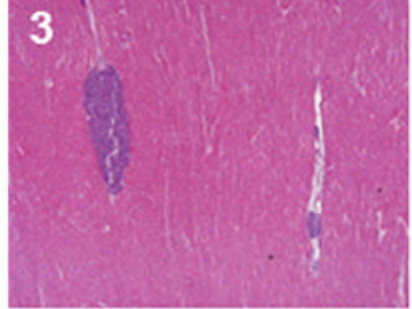

c. 1

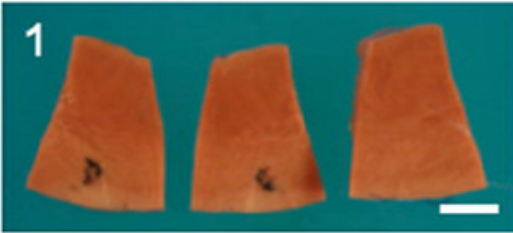

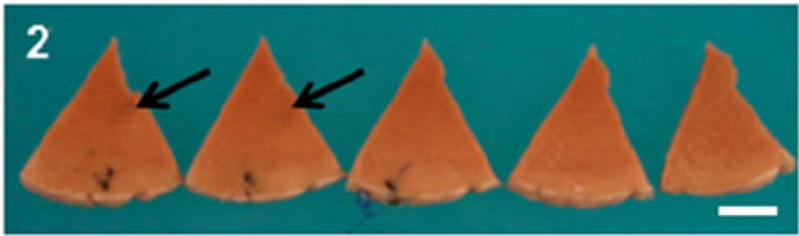

Figure 2.

Histopathologic Analysis of the Ex Vivo Perfusion Study. (a) Photograph of the perfused heart after formalin fixation. Arrows denote venous drainage of GNT-labeled MSCs above Site 2. Scale bar $=1 \mathrm{~cm}$. (b) Hematoxylin and eosin staining of Injections Sites 1, 2, and 3, illustrating the presence of the darkly-colored GNT-labeled MSCs. $\times 4$ Magnification. (c) Various levels of the tissue segments containing Injection Sites 1 and 2. Arrows denote an area of grayish discoloration, suggestive of disseminated GNT-labeled MSCs. Scale bar $=1$ $\mathrm{cm}$. 
a.

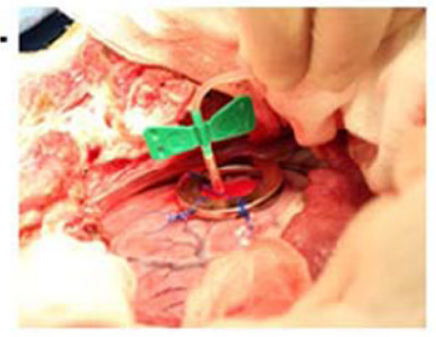

b.

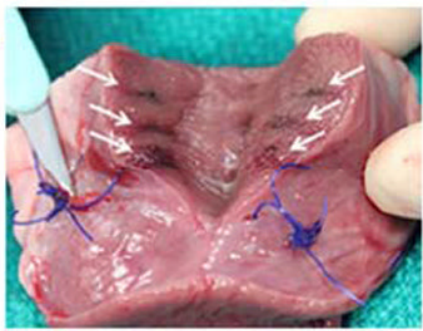

C.

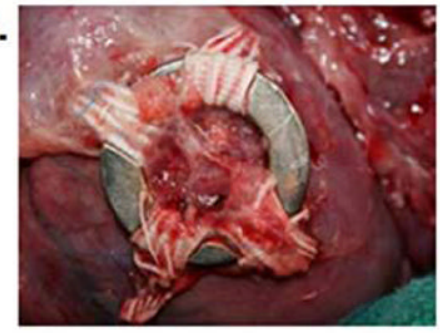

Figure 3.

Representative Photographs of the In Vivo Retention Study. (a) A butterfly needle was used to inject around a $1.3 \mathrm{~T} \mathrm{NdFeB}$ ring magnet sutured onto the left ventricular anterior wall.

(b) The white arrows indicate the presence of the GNTs near the injection sites. (c) An inflammatory response by the heart to the sutured magnet was observed after 48 hours. 

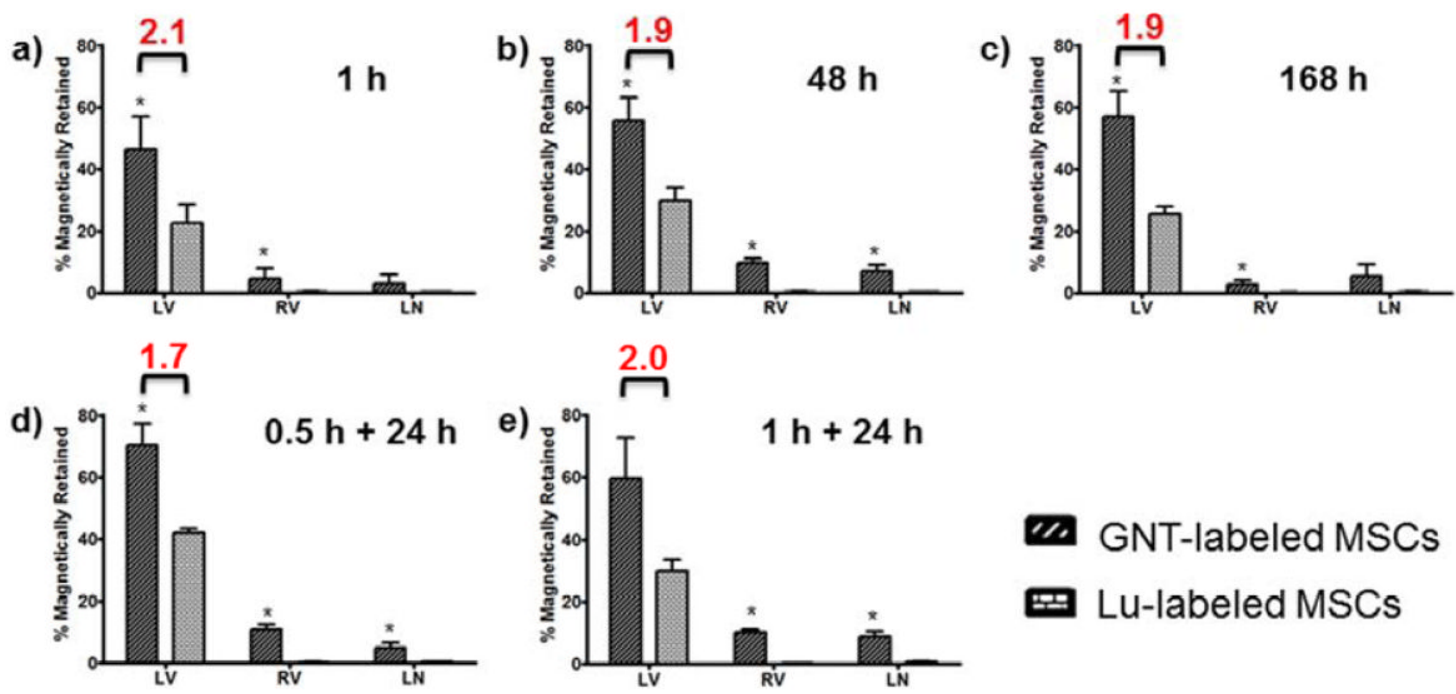

17. GNT-labeled MSCs

Lu-labeled MSCs
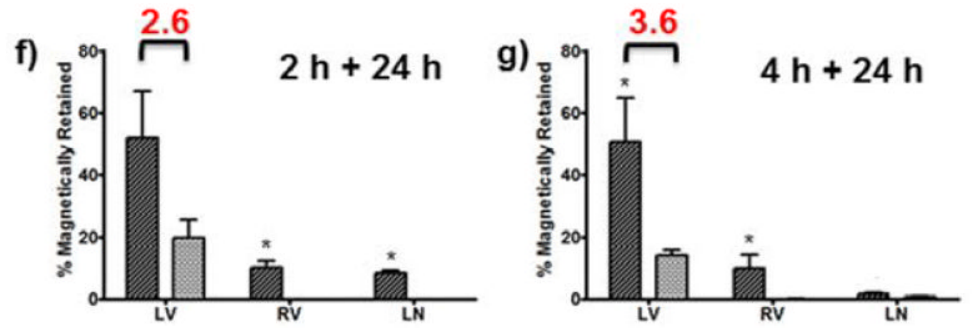

\section{LV: left ventricle \\ RV: right ventricle \\ LN: paratracheal/periaortic lymph nodes}

Figure 4.

Elemental Analysis of Groups A-G (a-g; $\mathrm{n}=3$ per group). The fold-increase is shown in red. $* \mathrm{p}<0.05$, compared to Lu-labeled MSCs. 